\title{
Organización territorial y funcional de la metrópoli de Buenos Aires
}

Natalia Usach. Universidad Nacional de la Patagonia San Juan Bosco, Comodoro Rivadavia, Argentina.

Rubén Garrido-Yserte. Universidad de Alcalá, Madrid, España.

María-Teresa Gallo-Rivera. Universidad de Alcalá, Madrid, España.

RESUMEN | Utilizando datos relacionales, de movilidad obligada, en combinación con indicadores de concentración y densidad de población y empleo, en este artículo se examina la reestructuración territorial en la metrópoli de Buenos Aires desde un enfoque funcional. Se muestra que el crecimiento metropolitano sigue pautas tanto de dispersión como de policentrismo, que se manifiestan en distintas partes de la metrópoli. Los subcentros de empleo presentan capacidad para estructurar el funcionamiento metropolitano y ejercer distinto grado de influencia en los respectivos corredores. Con todo, la ciudad central ejerce un papel estructurante principalmente respecto a los flujos laborales en ocupaciones cualificadas y de mayor formación, que provienen sobre todo de los corredores Norte y Noroeste. La complejidad de estos procesos debe ser considerada en la formulación de políticas públicas tendientes a atenuar los impactos no deseados de la dispersión, conforme se consolidan los subcentros de empleo como articuladores de la dinámica metropolitana.

PALABRAS CLAVE | áreas metropolitanas, reestructuración territorial, movilidad.

ABSTRACT | This article examines the territorial restructuring of the metropolis of Buenos Aires from a functional approach, using commuting relational data along with indicators of concentration and density of population and employment. It is observed that metropolitan growth follows patterns of dispersion and polycentricism, which appear in various areas of the metropolis. The sub centers of employment have the ability to structure the metropolitan operation and exercise different degrees of influence in the respective corridors. However, the central city plays a structuring role mainly in relation to the labor flows in higher skilled and trained occupations, which come mainly from the North and Northwestern corridors. The complexity of these processes must be considered in the formulation of public policies designed to mitigate the unwanted impacts of the dispersion, while the sub centers of employment are consolidated to articulate metropolitan dynamics.

KEYWORDS | metropolitan areas, territorial restructuring, mobility. 


\section{Introducción}

La relevancia que tiene la metrópoli de Buenos Aires en el sistema urbano argentino, tanto en lo relativo a concentración poblacional como a su estructura productiva, es incuestionable (concentra el $39 \%$ de la población total y el $32 \%$ del Producto Geográfico Bruto). A ello se suma que desde las últimas décadas del siglo pasado se encuentra inmersa en un complejo proceso de reestructuración territorial, que ha hecho evidente un claro patrón de expansión residencial hacia la periferia metropolitana, en paralelo a un renovado dinamismo del área central, la Ciudad Autónoma de Buenos Aires (CABA). La relevancia de estos fenómenos es clara y ha sido analizada bajo distintos enfoques por la literatura. Sin embargo, no se encuentran cabalmente estudiados los patrones de crecimiento policéntrico en esta área metropolitana, es decir, la existencia de subcentros que ejerzan influencia en la estructura urbana con relativa autonomía de la ciudad central, ni las relaciones funcionales que se producen en la principal aglomeración urbana de Argentina.

En este trabajo, el objetivo es aportar nuevas evidencias sobre la reestructuración metropolitana en Buenos Aires, reconociendo la existencia de patrones de crecimiento disperso y policéntrico desde un enfoque funcional. Se identifican los subcentros con capacidad para generar circuitos independientes a la CABA y se examinan las relaciones funcionales entre los distintos componentes de la metrópoli, lo que hace posible una caracterización de las áreas de influencia.

El artículo ofrece una breve revisión del policentrismo y la dispersión como dos procesos de estructuración territorial diferenciados por la capacidad de las áreas de aglomeración para influir en la estructura urbana. Tras describir la metodología y los datos que se utilizan en el análisis empírico, se examina preliminarmente información demográfica y de empleo, que aporta las primeras evidencias respecto a los cambios en los procesos de reestructuración metropolitana de Buenos Aires. Posteriormente se identifican los subcentros potenciales, se realiza el cálculo de los índices de movilidad laboral y se analizan las relaciones entre dichos índices, para determinar el grado de incidencia de los subcentros. La caracterización de las relaciones funcionales entre los subcentros y sus áreas de influencia (por tipo de relación laboral, de ocupación y nivel educativo de los trabajadores implicados en los flujos de movilidad) ocupa el apartado final.

\section{Transformaciones metropolitanas: de la ciudad fragmentada a la ciudad policéntrica}

El paso de la ciudad fragmentada a la ciudad policéntrica ha caracterizado las transformaciones de diversas metrópolis del mundo en los últimos años (Cuadrado \& Fernández, 2005; De Mattos, 2006, 2010; Duranton \& Puga, 2005; Trullén \& Boix, 2003). Y recientemente, dichos procesos han sido abordados para la realidad latinoamericana (Fernández-Maldonado, Romein, Verkoren \& Parente, 2014; Romein, Verkoren \& Fernández-Maldonado, 2009). Así, para el caso chileno, Truffello e Hidalgo (2015) estudian la evolución del área metropolitana de Santiago hacia una estructura urbana policéntrica como consecuencia de la aparición, 
consolidación y evolución de numerosos subcentros comerciales. También en Chile, para las regiones sur, Maturana y Arenas (2012) y Maturana, Vial y Poblete (2012) abordan el policentrismo, hallando bajos niveles en estas zonas. Para la Zona Metropolitana de México, Muñiz, Sánchez y García-López (2015) advierten la evolución hacia una estructuración tentacular que avanza sobre los corredores de actividad en los que se emplazan los subcentros de empleo, una tendencia ligada a la capacidad estructurante de las infraestructuras viarias, frente a la localización residencial cada vez más lejana a tales subcentros. Por su parte, Gonzales de Olarte y Del Pozo (2012) han confirmado recientemente el carácter policéntrico de Lima, usando para ello funciones de densidad y concentración de empleo.

Así, pues, existe evidencia de la coexistencia en el territorio de dinámicas conjuntas de difusión y concentración espacial selectiva de la población, de las actividades productivas y de las funciones económicas, que impactan directamente en la organización y funcionamiento de las ciudades. Se constatan no solo procesos de suburbanización a partir de la mera difusión residencial hacia las periferias, que las redes de autopistas y el automóvil posibilitan, sino también la formación de verdaderos subcentros metropolitanos especializados según las funciones empresariales que en ellos se localizan (Duranton \& Puga, 2005). Las estructuras metropolitanas tienden a ser cada vez más multipolares o policéntricas (Méndez, 2007) y nuevas centralidades se constituyen no solo como lugares de residencia, pauta típica de los procesos de sprawl y suburbanización, sino también como centros de producción, consumo, comercio, recreación y ocio, y de servicios a la producción y a las personas (Vecslir \& Ciccolella, 2011).

La metrópoli de Buenos Aires no ha sido ajena a estas transformaciones territoriales (Colella, 2013; Romein et al., 2009). La "suburbanización de las elites", impulsada especialmente durante los años noventa, contrasta social y espacialmente con la más antigua suburbanización de trabajadores urbanos que se produjo entre 1940 y 1960 (Torres, 2001). Tales contrastes se han traducido en la "ciudad fragmentada", pero también en procesos de crecimiento metropolitano en red, que han llevado a la conformación de una verdadera "ciudad-región", de bordes difusos y policéntricos (Borsdorf, 2003; Borsdorf \& Hidalgo, 2010; Prévôt-Schapira, 2000). Dichas tendencias han ido revelando las contradicciones y las disparidades socioterritoriales en las metrópolis latinoamericanas, impulsadas por factores de diversa índole; entre ellos, las condiciones macroeconómicas imperantes y las políticas que redujeron la acción directa del Estado a través de medidas tendientes a la desregulación, promoción y apertura al capital privado. Finalmente, tales disposiciones permitieron impulsar la modernización y la ampliación de las carreteras, la ejecución de grandes emprendimientos inmobiliarios (edificios inteligentes de alta gama, complejos empresariales para sedes corporativas y gated communities o urbanizaciones privadas cerradas y exclusivas), hoteleros y de restauración de nivel internacional, y grandes superficies comerciales y de ocio (Ciccolella, 1995, 1999; Ciccolella \& Vecslir, 2012; Clichevsky, 1999, 2012; Vecslir \& Ciccolella, 2011).

El término 'dispersión' se utiliza para caracterizar fenómenos de expansión urbana de diferente naturaleza: como suma exhaustiva de dimensiones descriptivas, como equivalente a suburbanización en tono peyorativo, como sinónimo de 
contraurbanización, también como proceso nocivo o como consumo excesivo de suelo más allá de la tasa de crecimiento de la población; como un proceso contrario al policentrismo, como difusión de servicios urbanos y como espacio desestructurado; implica la descentralización de la población y del empleo siguiendo un modelo desconcentrado, poco denso, discontinuo y falto de estructura, aleatorio o caótico (Muñiz \& García-López, 2013).

Por otra parte, no suele existir una división conceptual clara entre policentrismo y dispersión: el policentrismo es visto como una forma que puede adoptar la dispersión, como un proceso contrario a esta, como su estadio posterior superador o como una etapa previa a ella (García-López \& Muñiz, 2007; Muñiz \& GarcíaLópez, 2013). Se trata de un concepto versátil al que suele atribuírsele un contenido normativo, como objetivo de la política territorial tendiente a generar sistemas urbanos equilibrados, cohesionados y bien jerarquizados. Tómense como ejemplos la Estrategia Territorial Europea (Comisión Europea, 1999) o el Plan Estratégico Territorial 2010-2016 para el caso argentino (Subsecretaría de Planificación Territorial de las Inversiones Públicas [ssPTip], 2008).

Dos tipos de policentrismo destacan en la literatura: el morfológico y el funcional (Burger \& Meijers, 2012; Green, 2007; Trullén \& Boix, 2003). El primero alude a una distribución equilibrada de los centros, es decir, una desconcentración de ciertas variables demográficas y económicas en el territorio. El policentrismo funcional se refiere a una dimensión relacional, que considera las conexiones funcionales entre los núcleos, donde el equilibrio conjunto da lugar a relaciones multidireccionales entre los centros del sistema. Ambas perspectivas son complementarias, ya que la dimensión funcional no descarta el enfoque morfológico, sino que se extiende para incluir el patrón de interacción funcional entre los centros urbanos.

La perspectiva adoptada en este artículo considera la dispersión como un tipo de reestructuración metropolitana que genera espacios de simple concentración poblacional (subáreas), mientras que el policentrismo es entendido como un proceso que desencadena dinámicas de interacción entre núcleos con cierta jerarquía en el espacio metropolitano (subcentros) y sus áreas de influencia. Los subcentros se caracterizan por su autonomía respecto a la ciudad central y porque en ellos se establece una serie de funciones que sirven y transforman las relaciones en un ámbito territorial más amplio (Borsdorf, 2005); constituyen verdaderos elementos integradores y polos de atracción en los subsistemas urbanos en los que tiene lugar una dialéctica con los territorios aledaños, entre los que se establecen flujos de interacción de distinta naturaleza (Roca, Arellano \& Moix, 2011; Roca, Marmolejo \& Moix, 2009).

Junto con estas grandes tendencias, está emergiendo un renovado dinamismo de las áreas centrales de las metrópolis, que podría estar poniendo coto al periodo de acelerada suburbanización a expensas de la vitalidad de la ciudad central. Este fenómeno ha sido identificado como "la gran inversión" y constatado en el 37\% de las áreas metropolitanas estadounidenses de más de un millón de habitantes, donde las ciudades centrales han crecido más rápido que las zonas suburbanas entre $2010 \mathrm{y}$ 2013 (Ehrenhalt, 2012; Florida, 2014; Frey, 2014). El fenómeno ha sido relevante en aquellas metrópolis que han tenido importantes estrategias de regeneración urbana; en los centros dinámicos posindustriales, de alta tecnología; en los ligados a la economía 
del conocimiento y los high amenity downtowns; entre ellos, Nueva York, Los Ángeles, Boston, Washington, DC, Denver, Seattle o San José, en el Silicon Valley.

En resumen, para el caso de Buenos Aires, comprender la complejidad de su reestructuración territorial requiere, por una parte, explorar la presencia de patrones mixtos de dispersión y policentrismo, considerando las relaciones funcionales entre los nodos metropolitanos de tal forma que permita desvelar sus niveles de dependencia respecto a la CABA y la emergencia subcentralidades con dinámicas internas propias; y por otra, reconocer al mismo tiempo la renovada vitalidad de la ciudad central.

\section{Metodología y datos utilizados}

La perspectiva habitualmente adoptada en los análisis sobre policentrismo ha sido el análisis de funciones de densidad de algunas variables de stocks (empleo y población especialmente) y la observación de sus cambios en un periodo de tiempo determinado, en lugar del enfoque funcional (Burger \& Meijers, 2012; Green, 2007). Esta orientación, aunque válida, no captura las relaciones funcionales entre los diferentes espacios metropolitanos ni el grado de incidencia de los posibles subcentros en su entorno, ya que el mero volumen y la concentración de estas variables en algunas áreas de la metrópoli no constituyen un indicador suficiente para revelar la existencia de subcentros (García-López \& Muñiz, 2007).

Resulta relevante medir, de algún modo, las relaciones funcionales existentes en el territorio a partir de la identificación de subcentros y de su capacidad de influencia en su entorno inmediato. Los flujos de movilidad por motivos de trabajo, commuting, permiten aproximar las relaciones e influencias de y entre los subcentros y su entorno (Marmolejo, 2011; Roca et al., 2009, 2011; Trullén \& Boix, 2003), como mecanismo para identificar la existencia de estructuras dispersas y policéntricas. En efecto, los flujos de movilidad entre el lugar de residencia y el de trabajo resultan indicadores pertinentes para estimar las interacciones intrametropolitanas.

En los modelos monocéntricos, los flujos de commuting van desde los núcleos periféricos de menor tamaño hacia la ciudad central, mientras que en el policentrismo los flujos no están centralizados, sino que son recíprocos: pueden originarse tanto desde el centro metropolitano con destino a los diferentes núcleos suburbanos (reverse commuting), así como desde ellos hacia otros centros periféricos, o bien estar crecientemente autocontenidos, en el sentido de que una parte importante de los residentes trabaja en el propio subcentro metropolitano, con bastante autonomía de la ciudad central.

Por lo dicho, la metodología aquí empleada combina indicadores tradicionales de concentración y densidad de población y empleo con datos de flujos de movilidad laboral, a fin de aproximar el grado de dependencia funcional de la ciudad central e identificar la existencia de subcentralidades relevantes indicativas de una estructura metropolitana policéntrica.

Los datos de empleo y población proceden de la información censal de los años 2001 y 2010, publicada por el Instituto Nacional de Estadísticas y Censos (Indec). Los relativos a la movilidad residencia-trabajo corresponden a la Encuesta de Movilidad Domiciliaria (Enmodo) 2009-2010, de la Secretaría de Transporte de la Nación, efectuada en 27 partidos (municipios) y la CABA. Esta encuesta fue realizada entre 
finales de 2009 y principios de 2010 y en ella se recolectó información sobre movilidad en 22.500 hogares; se incluyó, además de las características del hogar y de las personas, todos los viajes de los integrantes del hogar del día anterior, con sus respectivas etapas. Se trata de la primera encuesta de movilidad efectuada en esta metrópoli con bases de datos de acceso público. ${ }^{1}$ De esta fuente, se seleccionaron los viajes de las personas ocupadas que tienen como origen el hogar y como destino el lugar de trabajo, obteniéndose una matriz origen-destino que involucra 28 jurisdicciones, las cuales conforman el área de estudio donde se han registrado datos de movilidad laboral. De ellas, 24 jurisdicciones integran el llamado "conurbano bonaerense", que en rigor -junto con la CABA- forman el área metropolitana. El área de estudio de este trabajo abarca, por tanto, ese ámbito, más tres partidos que están por fuera del conurbano -Presidente Perón, Pilar y Escobar-, pero que forman parte de la Región Metropolitana de Buenos Aires (RMBA). ${ }^{2}$ En la figura 1 se muestran las jurisdicciones que componen la RMBA y las que componen el área de estudio.

\section{FIgURA I | Área de estudio}

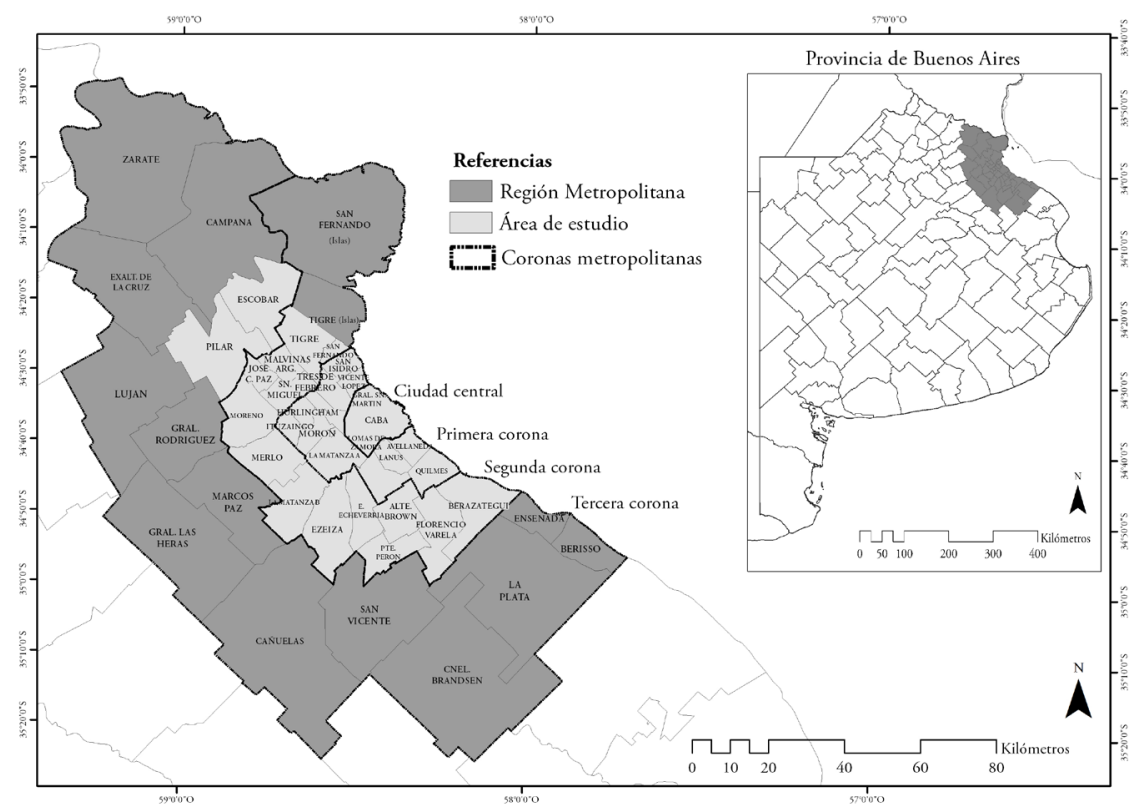

FUENTE ELABORACIÓN PROPIA

1 Base disponible en http://www.ptuma.gob.ar/publicaciones/index.html

2 La RMBA comprende: la CABA (con un área de $200 \mathrm{~km}^{2}$ ); el conurbano bonaerense, compuesto por 24 partidos (Almirante Brown, Avellaneda, Berazategui, E. Echeverría, Ezeiza, Florencio Varela, General San Martín, Hurlingham, Ituzaingó, José C. Paz, La Matanza, Lanús, Lomas de Zamora, Malvinas Argentinas, Merlo, Moreno, Morón, Quilmes, San Fernando, San Isidro, San Miguel, Tigre, Tres de Febrero y Vicente López, con un área de $3.680 \mathrm{~km}^{2}$ ); y el resto de la $R M B A$, integrado por 16 partidos (Berisso, Brandsen, Campana, Cañuelas, Ensenada, Escobar, Exaltación de la Cruz, Gral. Las Heras, General Rodríguez, La Plata, Luján, Marcos Paz, Pilar, Presidente Perón, San Vicente y Zárate, con un área de $15.800 \mathrm{~km}^{2}$ ). 
El análisis de las pautas de dispersión y policentrismo se ha realizado en tres etapas: en la primera, se identifican los posibles subcentros; en la segunda, se efectúa el cálculo de los índices de movilidad laboral para establecer la incidencia de los subcentros en su entorno (corredores metropolitanos); y en la tercera, se tipifican las tendencias de los subcentros hacia la dispersión y el policentrismo, considerando los índices de movilidad obtenidos y los datos de concentración laboral.

La primera etapa de identificación de los posibles subcentros, a los que también se denominará "centros de empleo", se efectúa mediante la determinación de umbrales de concentración laboral, calculando porcentajes y densidad de empleo para cada uno de los partidos sobre los que se tienen datos de movilidad. En esta primera parte cobra especial relevancia la definición de un área de influencia de los posibles subcentros identificados, a partir de la cual se medirá posteriormente el grado de interacciones. Parece coherente considerar como áreas de influencia aquellos corredores metropolitanos que han surgido de la organización del territorio por grandes ejes de circulación (Vecslir \& Ciccolella, 2011). Se sigue, por lo tanto, la zonificación en seis corredores efectuada por la Secretaría de Transporte de la Nación en función de los patrones de circulación y orientación de las principales vías de comunicación (red principal de autopistas, carreteras y ferrocarriles), que -como se observa en la figura 2 - en su mayoría convergen a la ciudad de Buenos Aires.

\section{FIGURA 2 Corredores metropolitanos e infraestructuras de comunicación terrestre}

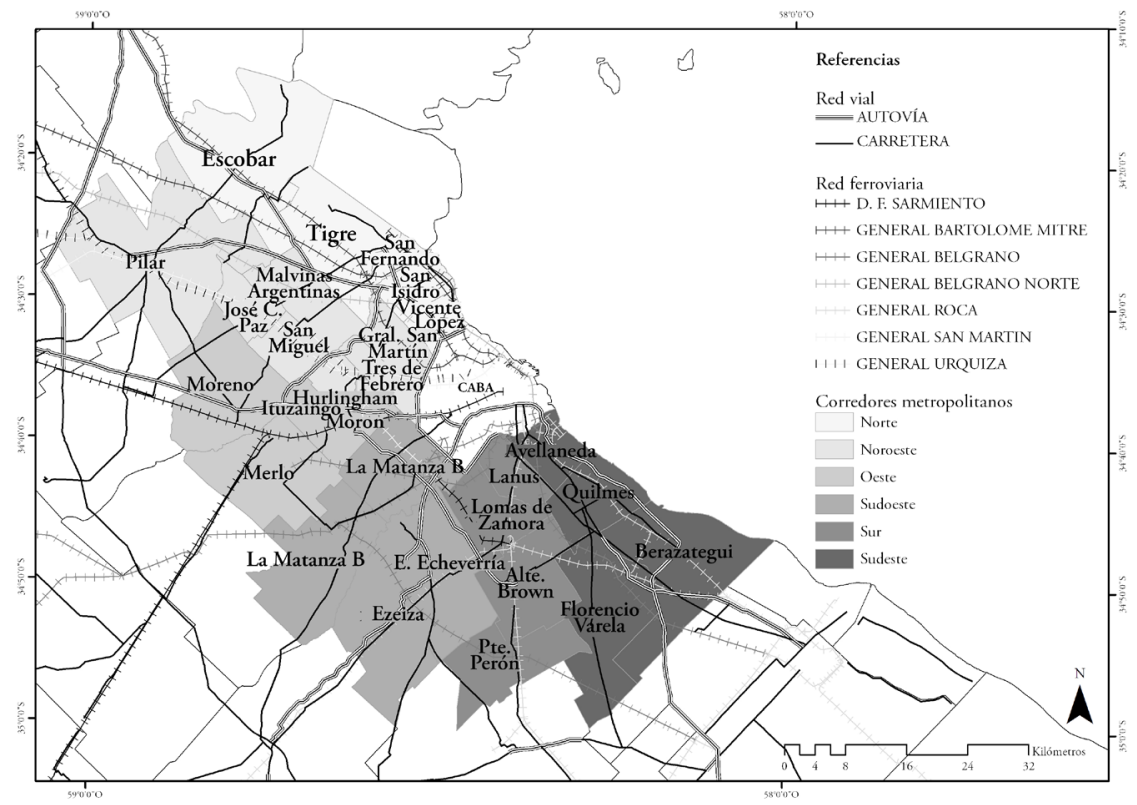

FUENTE ELABORACIÓN PROPIA 
La segunda etapa consiste en el análisis de la incidencia de los centros de empleo en su entorno, que se efectúa siguiendo el criterio de la movilidad laboral generada desde cada corredor hacia los diferentes destinos, como proxy de las interacciones espaciales (Gallo \& Garrido, 2012; Gallo, Garrido \& Vivar, 2010). Para ello se construyen tres índices de movilidad laboral:

a. El indice de cohesión interna: informa del grado de autocontención de territorio considerado y el peso de sus subcentros. Se define como el porcentaje de viajes que tienen como destino el mismo corredor.

b. El indice de dependencia funcional: da cuenta de la relevancia de la ciudad central y de la pervivencia de la tradición monocéntrica del área. Es definido como el porcentaje de viajes que tienen como destino la ciudad central, en este caso la CABA, sobre el total de viajes originados.

c. El indice de dispersión: captura la dinámica del modelo de dispersión. Se define como el porcentaje de viajes que tienen como destino partidos diferentes a los del corredor y a la ciudad central.

De este modo, se busca capturar la capacidad de los subcentros y sus entornos para generar dinámicas laborales internas relevantes respecto de las relaciones con la ciudad central u otras áreas. La interpretación conjunta que se da a los índices es que mientras más cohesión exista al interior de un área, y menos dependencia se genere del centro, se estará en presencia de subcentros y de una dinámica metropolitana policéntrica.

Una tercera parte del análisis consiste en sintetizar los índices de movilidad y los datos de concentración laboral. Para tipificar el grado de influencia de los subcentros se siguen los siguientes criterios:

- Áreas de influencia de incidencia alta: corredores que presentan índices de cohesión superiores al 55\% y, además, índices de dependencia inferiores al 30\%.

- Áreas de influencia de incidencia media-alta: corredores que presentan índices de cohesión por encima del 50\%, pero cuyos índices de dependencia son iguales o superiores al $30 \%$.

- Áreas de influencia de incidencia media-baja: corredores cuyos índices de cohesión, si bien superan el 50\%, son los menores del conjunto del área, y cuyos índices de dependencia son iguales o superiores al $30 \%$.

Finalmente, se analizan y caracterizan las dinámicas identificadas a fin de reconocer las peculiaridades de las interacciones metropolitanas, considerando las características de los flujos laborales en términos de variables como el tipo de relación laboral, tipo de ocupación y nivel educativo de los trabajadores que realizan viajes por motivos de trabajo. 


\section{Evidencias sobre las transformaciones territoriales en el Buenos Aires metropolitano}

Desde el punto de vista demográfico, la dinámica metropolitana de Buenos Aires entre 1960 y 2010 se caracterizó por la retracción de la ciudad central (-2,6\%) y el progresivo crecimiento de los corredores metropolitanos, aunque de manera diferenciada: sobresale el corredor sudoeste, donde la población aumentó un 375,2\%, frente al corredor norte, que tuvo el cambio menos marcado (98,2\%) (figura 3).

FIGURA 3 Población: distribución relativa en 2010 y tasa de variación 1960-2010 y 2001-2010, por corredores metropolitanos у САВА

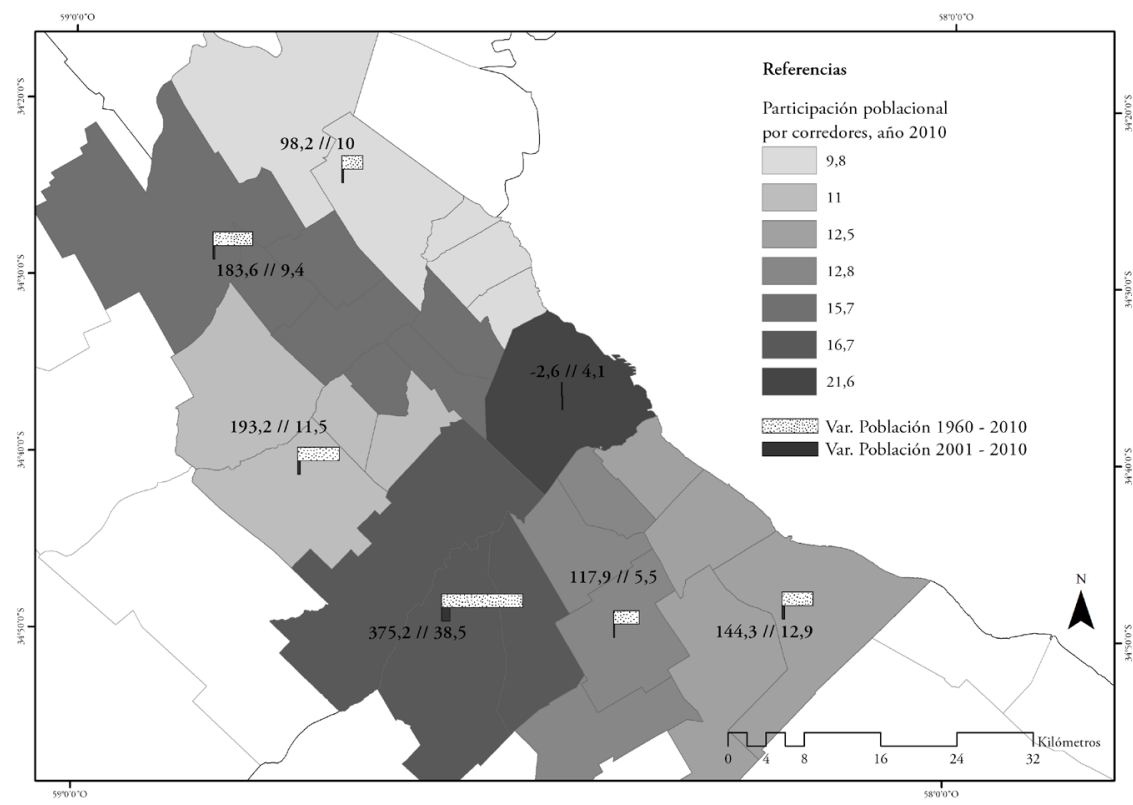

FUENTE ELABORACIÓN PROPIA CON DATOS DEL INSTITUTO NACIONAL DE ESTADÍSTICAS Y CENSOS (INDEC)

Sin embargo, considerando el último periodo intercensal (2001-2010), puede notarse un renovado dinamismo demográfico de la CABA, donde la tasa de variación fue del $4,1 \%$. Aunque ese porcentaje es inferior al incremento porcentual de la población total y de la población urbana nacional (10,6\% y 12,6\%, respectivamente), resulta llamativo tras décadas de retracción poblacional en la ciudad de Buenos Aires. En el mismo lapso, los corredores también incrementaron su población, pero en proporciones mayores a la ciudad central. El caso del corredor Sudoeste vuelve a ser el más significativo: creció un 38,5\% (por el impulso demográfico registrado en los partidos de La Matanza, Ezeiza y Esteban Echeverría). Le sigue el corredor Sudeste, con una tasa que roza el 13\%, con especial dinamismo de los partidos de Florencio Varela, Berazategui y Quilmes (figuras 3 y 4). En general, los partidos más dinámicos demográficamente son los de la segunda y tercera corona (figura 4). 
FIGURA 4 | Población: distribución relativa en 2010 y tasa de variación 20012010, por partidos y CABA

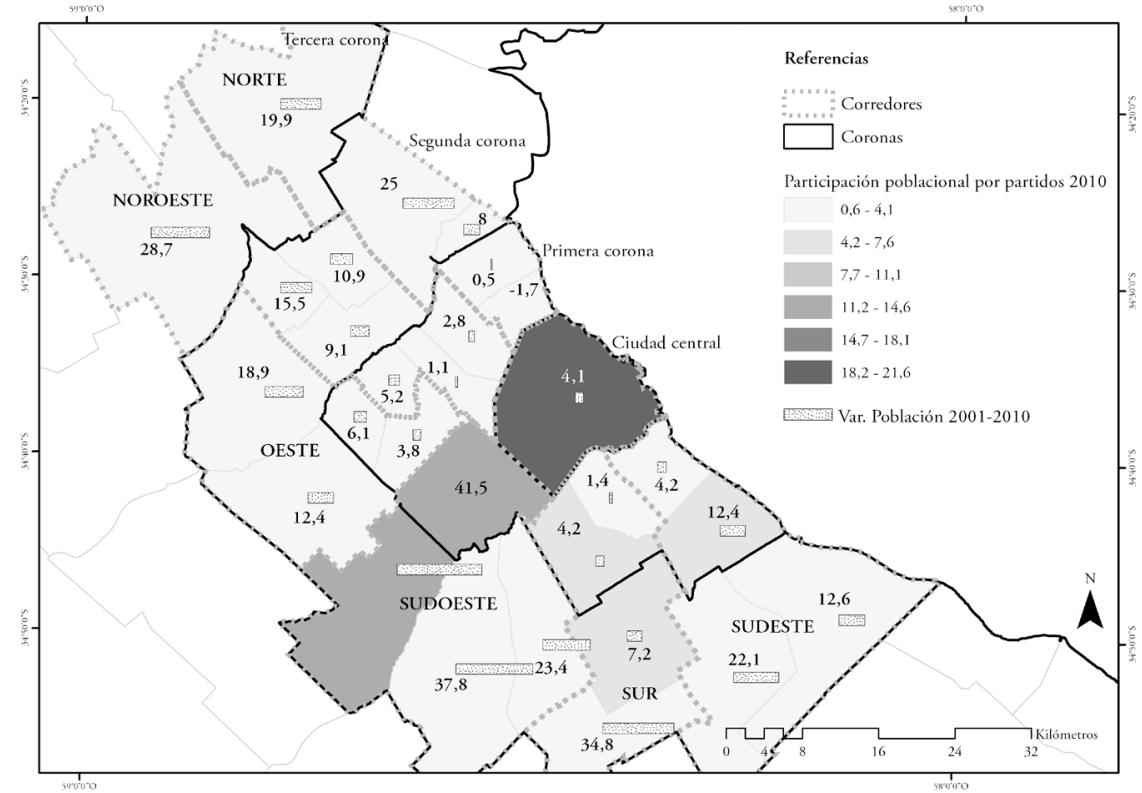

FUENTE ELABORACIÓN PROPIA CON DATOS DEL INSTITUTO NACIONAL DE ESTADÍSTICAS Y CENSOS (INDEC)

Desde 1960, en distinta medida, todos los corredores metropolitanos incrementaron su participación en la población total del área, frente a la pérdida de peso de la ciudad central en casi 22 puntos porcentuales (tabla 1). Con todo, tal crecimiento no ha revertido la preponderancia demográfica de la CABA respecto al resto de la metrópoli. Los datos censales sugieren que si bien en la última década la población asentada en la CABA ha vuelto a crecer, no podría afirmarse aún la presencia de un proceso de reconcentración poblacional, aunque sí resulta un dato necesario de ser considerado. Así, en principio, se confirma un proceso a favor de la desconcentración poblacional hacia los corredores metropolitanos y hacia las coronas más alejadas de la ciudad central.

Entre 1960 y 2010, el corredor norte experimentó un cierto estancamiento, en torno al $10 \%$, con leves incrementos y suaves bajas en la participación poblacional respecto al resto del área. La participación poblacional del corredor noroeste presentó un ritmo constante de incremento hasta 2001, aunque en 2010 el mismo cayó, reuniendo al 15,7\% de la población metropolitana. Los corredores oeste y sur han seguido un comportamiento similar de lento incremento en su participación en la distribución de la población metropolitana, aglutinando, en el último censo, el $11 \%$ y el $12,8 \%$, respectivamente. El eje más dinámico del periodo es el sudoeste, que, partiendo de un magro 6,9\% en 1960, aglutinaba en 2010 el 16,7\% de la población del área. Finalmente, el corredor sudeste, con una evolución positiva desde 1960, reunía en 2010 al 12,5\% de la población del área estudiada. 
El referido dinamismo demográfico reciente experimentado por la CABA probablemente esté asociado al hecho de que, desde hace algo más de dos décadas, el área central tradicional viene experimentando un proceso de densificación, modernización y verticalización (Ciccolella \& Vecslir, 2012). A la vez, ha mantenido su preeminente centralidad en cuanto a la concentración de funciones político-administrativas, así como en lo referente a la localización residencial de alto y medio alto nivel socioeconómico (Torres, 2001), posibilitada por la oferta de desarrollos inmobiliarios de alta gama. A esto cabría agregar la preponderancia de la ciudad central en la concentración del poder económico como centro de negocios y comando, impulsada por los emprendimientos inmobiliarios de construcción y reconversión de edificios corporativos (Ciccolella \& Vecslir, 2012). Un claro ejemplo lo constituye la operación urbanística Puerto Madero (Clichevsky, 2012; Mignaqui, 2012; Núñez \& Ruiz, 2013).

TABLA I | Población: distribución relativa entre 1960 y 2010. Empleo: distribución relativa y proporción cada mil habitantes, 2001-2010. Ambos por corredores metropolitanos y CABA

\begin{tabular}{|c|c|c|c|c|c|c|c|c|}
\hline & & $\begin{array}{l}\text { CIUDAD } \\
\text { CENTRAI }\end{array}$ & NORTE & NOROESTE & OESTE & SUDOESTE & SUR & SUDESTE \\
\hline \multirow{6}{*}{ Población (\%) } & 1960 & 43,5 & 9,7 & 10,9 & 7,4 & 6,9 & 11,5 & 10,1 \\
\hline & 1970 & 35,2 & 10,1 & 12,3 & 9,3 & 9,1 & 13,1 & 10,9 \\
\hline & 1980 & 29,4 & 10,1 & 13,3 & 10,9 & 11,5 & 13,2 & 11,6 \\
\hline & 1991 & 26,5 & 10,0 & 13,8 & 11,8 & 12,5 & 13,3 & 12,1 \\
\hline & 2001 & 23,3 & 10,0 & 16,1 & 11,0 & 13,6 & 13,6 & 12,4 \\
\hline & 2010 & 21,6 & 9,8 & 15,7 & 11,0 & 16,7 & 12,8 & 12,5 \\
\hline \multirow{2}{*}{ Empleo (\%) } & 2001 & 31,5 & 10,7 & 14,6 & 9,4 & 11,1 & 12,1 & 10,7 \\
\hline & 2010 & 24,2 & 10,0 & 15,3 & 10,4 & 16,2 & 12,2 & 11,6 \\
\hline \multirow{2}{*}{$\begin{array}{l}\text { Empleo } \\
\text { por } 1.000 \\
\text { habitantes }\end{array}$} & 2001 & 419,0 & 331,1 & 280,5 & 263,5 & 252,5 & 275,3 & 265,3 \\
\hline & 2010 & 572,4 & 521,0 & 497,7 & 481,7 & 495,4 & 489,1 & 474,4 \\
\hline
\end{tabular}

FUENTE ELABORACIÓN PROPIA CON DATOS DEL INSTITUTO NACIONAL DE ESTADÍSTICAS Y CENSOS (INDEC)

Desde el punto de vista del empleo, los patrones de concentración laboral son análogos a los poblacionales (figuras 5 y 6). Los datos disponibles muestran que, en términos relativos, entre 2001 y 2010 la variación más moderada se registró en la CABA $(42,2 \%)$ y la más significativa en el corredor sudoeste $(171,7 \%)$, en este último caso como consecuencia de los incrementos que experimentaron los partidos que componen el corredor: La Matanza (185\%), Ezeiza (154,1\%) y Esteban Echeverría (117,2\%). 
FIGURA 5 | Empleo: distribución relativa en 2010 y tasa de variación 2001-2010, por corredores y CABA

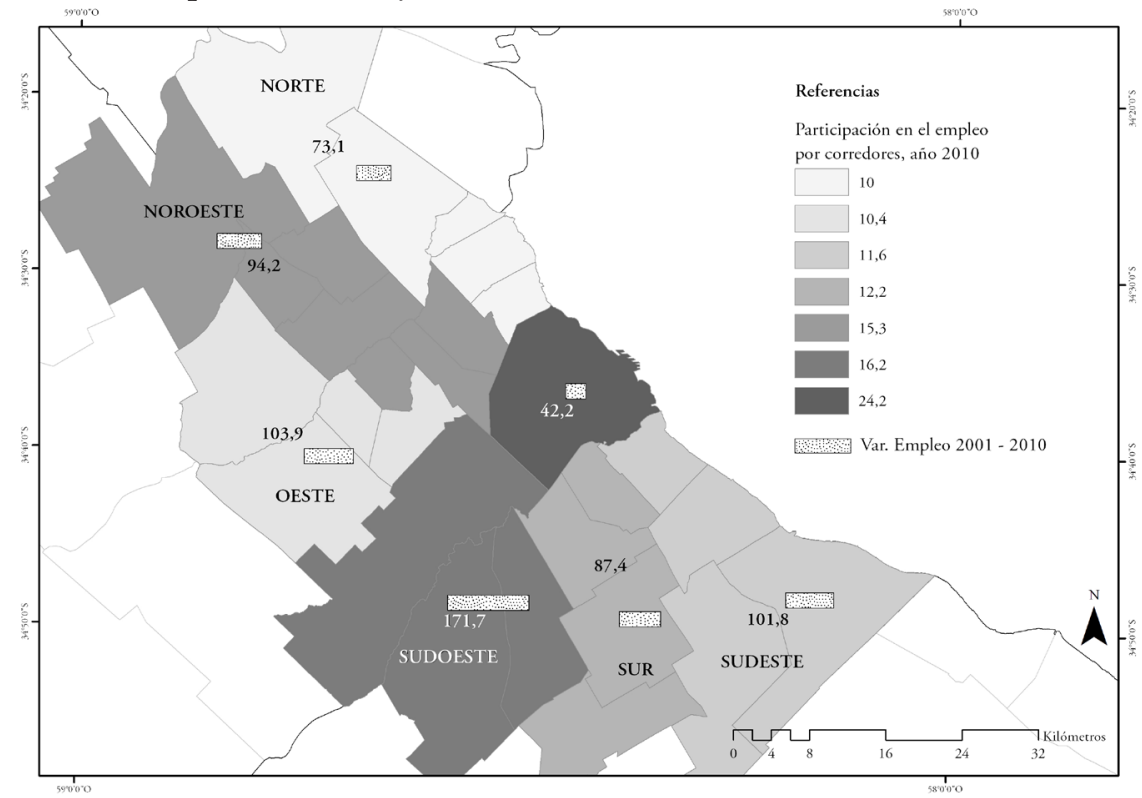

FUENTE ELABORACIÓN PROPIA CON DATOS DEL INSTITUTO NACIONAL DE ESTADÍSTICAS Y CENSOS (INDEC)

FIGURA 6 | Empleo: distribución relativa en 2010 y tasa de variación 2001-2010, por partidos y CABA

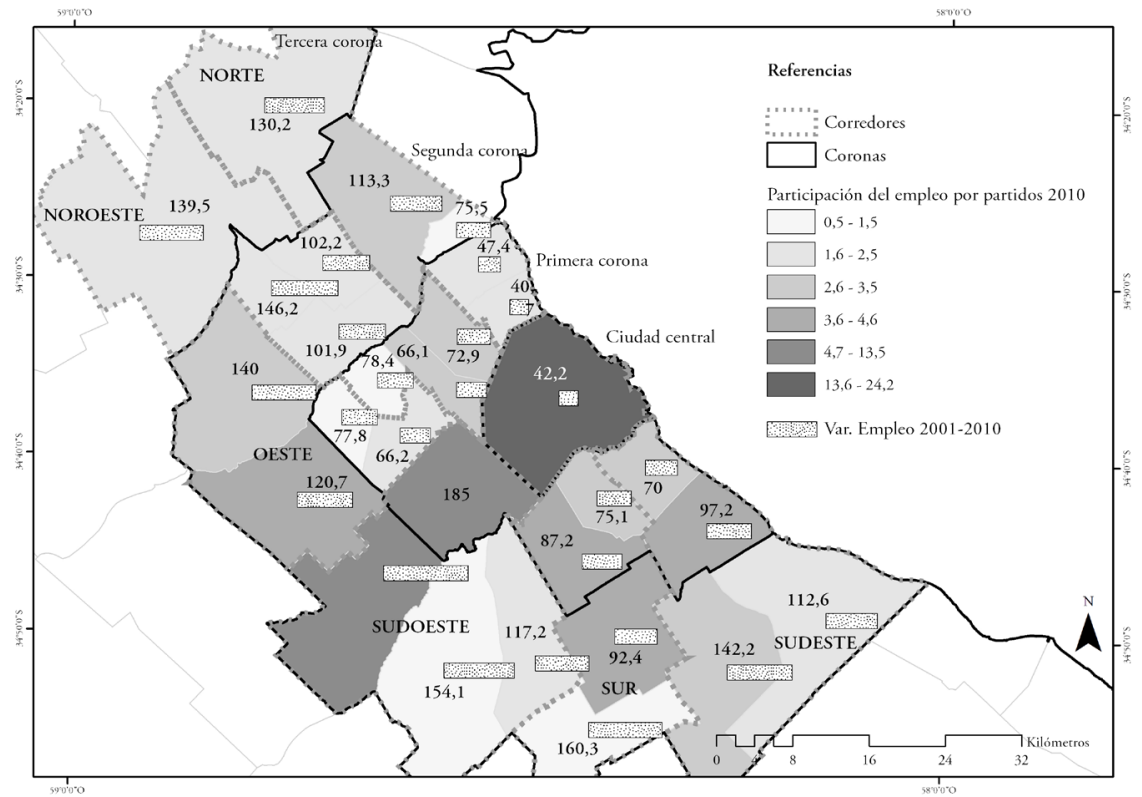

FUENTE ELABORACIÓN PROPIA CON DATOS DEL INSTITUTO NACIONAL DE ESTADÍSTICAS Y CENSOS (INDEC) 
Es relevante observar que el empleo metropolitano acusó cierta redistribución (tabla 1), dado que la ciudad central concentraba en 2010 una proporción menor de empleo que en 2001 (pasó del 31,5\% al 24,2\% de participación), mientras que el corredor sudoeste vio incrementada su participación del $11,1 \%$ al 16,2\%. En términos de empleo por cada mil habitantes, la ciudad central y los corredores norte y noroeste mostraban los índices más altos en 2010. El principal cambio observado es el incremento del empleo en el sudoeste, corredor que pasó de tener el índice más bajo en 2001 (252 empleados por cada mil habitantes) a ocupar el cuarto lugar con 495 en 2010.

En resumen, la evolución de los datos censales de población y empleo permiten afirmar que, junto con la desconcentración de la población, se ha producido una desconcentración del empleo hacia los corredores, en especial en la segunda y tercera corona. Si bien las mayores concentraciones de población y empleo, aparte de la CABA, se encuentran en el sudoeste y en el noroeste, la mayor variación poblacional y también de empleo (2001-2010) se presenta claramente en el sudoeste, seguido por el corredor sudeste en términos de variación de población y por el eje oeste en lo referente al empleo. Desde otro ángulo, destaca la importancia del corredor norte en términos del empleo por mil habitantes, aunque ninguno de los corredores presenta un índice superior al de la ciudad central. Por lo tanto, los procesos de dispersión de la población y el empleo hacia los corredores son realmente claros en esta metrópoli. Lo que queda por conocer ahora es si existen pautas de policentrismo, es decir, subcentralidades potentes que organicen el espacio metropolitano; y, en su caso, caracterizar las relaciones funcionales en las áreas de influencia de los subcentros. Las secciones siguientes se dedican a ello.

\section{Dinámica e interacción de los subcentros en sus áreas de influencia}

\section{Identificación y análisis de los subcentros}

Los datos de la Enmodo confirman que la CABA, además de ser el principal centro de población y empleo, genera y es receptora de importantes flujos en relación con el resto del área; genera más del $26 \%$ del total de viajes laborales y a su vez recibe el $45 \%$ de todos los viajes producidos en el área metropolitana. En la CABA, el 88,2\% de la población residente se moviliza dentro de la ciudad central para desempeñar su actividad laboral y el flujo de ellos que viaja hacia los corredores lo hace principalmente hacia el norte, noroeste y sudoeste, destacando en la primera corona los partidos de Vicente López, San Isidro, General San Martín y La Matanza A. Los partidos de la corona más cercana a la ciudad central tienen una importancia relativamente similar como destino de trabajo para la población residente en ella, mientras que la importancia relativa de la CABA es menor como destino laboral para los partidos de la segunda corona.

Por otra parte, en los seis corredores, el porcentaje de residentes que se mueven dentro del corredor respectivo es mayor que el de quienes lo hacen hacia la ciudad central; y si bien, en términos agregados, la CABA recibe, como se apuntó, el 45\% de los trabajadores, no es para cada uno de los ejes el principal destino laboral. En definitiva, tal situación da cuenta de la complejidad de las relaciones funcionales 
que se generan en la metrópoli y aporta indicios claros respecto a la existencia de una dinámica interna en las periferias metropolitanas, donde posiblemente existen importantes subcentros de empleo que están alterando la tradicional jerarquía de la ciudad central y las relaciones centro-periferia.

Para la identificación de los subcentros se aplican umbrales estadísticos flexibles en 2001 y 2010 al porcentaje de empleo y a las condiciones de densidad (GarcíaLópez \& Muñiz, 2007; Muñiz \& García-López, 2013). Se considera como subcentros a los partidos con una densidad de empleo por encima de la densidad media y que cuenten además con un porcentaje de empleo superior al 1\% del total. De este modo, se obtiene que en 2001 el número de partidos que cumplen con ambas condiciones y que, por tanto, pueden ser clasificados como subcentros de empleo, son 11; mientras que en 2010 son 12, incorporándose La Matanza a los identificados en 2001.

Como puede apreciarse (tabla 2), la concentración del empleo en la CABA se ha reducido del $31,5 \%$ al $24,2 \%$, mientras que los subcentros han incrementado significativamente la concentración; pero ello ha ocurrido no solo a costa de la primera, sino también porque en el conjunto del resto de los partidos se ha reducido la concentración.

TABLa 2 Evolución de la distribución del empleo

\begin{tabular}{|l|c|c|}
\cline { 2 - 3 } \multicolumn{1}{c|}{} & 200I & 20IO \\
\hline No de subcentros & 11 & 12 \\
\hline$\%$ empleo en el CABA & $31,5 \%$ & $24,2 \%$ \\
\hline$\%$ empleo en subcentros & $32,1 \%$ & $42,8 \%$ \\
\hline$\%$ empleo otros partidos & $36,4 \%$ & $33,0 \%$ \\
\hline
\end{tabular}

FUENTE ELABORACIÓN PROPIA CON DATOS DEL INSTITUTO NACIONAL DE ESTADÍSTICAS Y CENSOS (INDEC)

Se estaría, por lo tanto, produciendo un reequilibro a favor de los corredores donde se emplazan los subcentros identificados. Es importante notar que si bien las subcentralidades se distribuyen entre los distintos corredores (véase figura 7), casi en su totalidad, salvo San Fernando, se emplazan en la primera corona, la zona más próxima a la ciudad central, en concordancia con la tendencia identificada por Fernández-Maldonado et al. (2014) en varios casos latinoamericanos (Ciudad de México, Lima y Fortaleza). La distribución de los subcentros identificados en 2010 es como sigue: en cada uno de los corredores norte y noroeste se localizan tres subcentros de empleo; en los corredores oeste y sudoeste, un subcentro en cada uno; y en los corredores sur y sudeste, dos subcentros, uno en cada corredor. 
FIgURA 7 Distribución de los subcentros identificados en los corredores metropolitanos, 2010

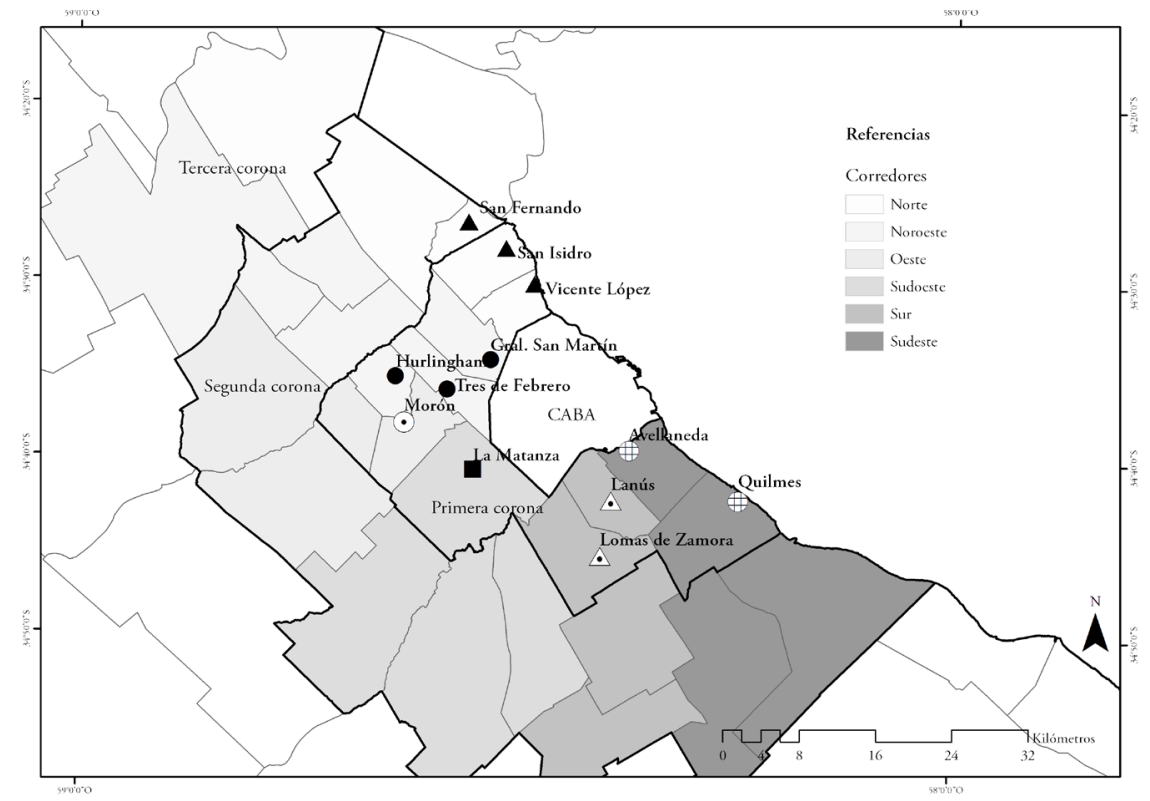

FUENTE ELABORACIÓN PROPIA

\section{Análisis de las áreas de influencia}

Tomando los viajes que se originan en cada uno de los corredores metropolitanos en los que se emplazan los subcentros identificados y sus diferentes destinos, se han calculado los índices de cohesión interna, dependencia funcional y dispersión, para 2010 (figura 8).

En primer lugar, se observa que todos los corredores tienen índices de dependencia inferiores al 35\% y que los índices de cohesión superan el 50\% del total de flujos laborales en todos los corredores, siendo siempre superiores a los índices de dispersión. Con respecto a la ciudad central, el porcentaje de viajes con motivo de trabajo que se originan desde esta área con destino hacia otros corredores no es elevado (apenas llega al 11,8\%), mientras que el resto de los viajes laborales generados en la CABA tienen como destino la propia ciudad $(88,2 \%)$.

En la tabla 3 se ofrece un resumen de las relaciones entre los índices de movilidad obtenidos y los datos de concentración laboral por corredores, con el fin de clasificarlos según el grado de incidencia de los subcentros.

En la primera clasificación, áreas de influencia de incidencia alta de los subcentros, se encuadran los corredores norte y noroeste. El eje norte presenta el mayor índice de cohesión interna (65\%) y la menor dispersión (apenas el 8\% de los viajes laborales tiene como destino otros corredores), siendo su grado de dependencia funcional relativamente bajo (28\%). Además, es el eje donde en menor medida aumentó el empleo $(73,1 \%)$, pero en el cual se registra la mayor cantidad de 
trabajadores por cada mil habitantes. Los resultados confirman la idea de que este corredor es el más consolidado internamente, con mayor estabilidad en el empleo y donde una importante proporción de sus residentes trabaja en el propio corredor, lo que implicaría una incidencia alta de los subcentros de empleo.

$\mathrm{Al}$ analizar los índices de movilidad individualmente por subcentros, destaca en el corredor norte el partido de Vicente López, limítrofe a la CABA, que ostenta un índice de dependencia funcional que se aparta de la media del corredor: 47\% de los viajes laborales tiene como destino la ciudad central. Este dato no resulta sorprendente, dado que la vinculación, expansión y consolidación metropolitana desde la zona norte de la CABA hacia los partidos del corredor norte se han visto reforzadas en las dos últimas décadas por la localización de algunas actividades del terciario superior (sedes de grandes empresas nacionales y multinacionales, junto a otras pequeñas y medianas; despachos profesionales y servicios, etcétera) y de importantes cadenas internaciones de consumo (Vecslir \& Ciccolella, 2011). Se ha conformado así un continuum metropolitano, donde el mercado de trabajo es compartido. De hecho, la vinculación al norte es tal que el partido de Vicente López conforma el principal destino de los trabajadores que residen en la CABA.

FIGURA 8 | Índices de movilidad laboral, 2010

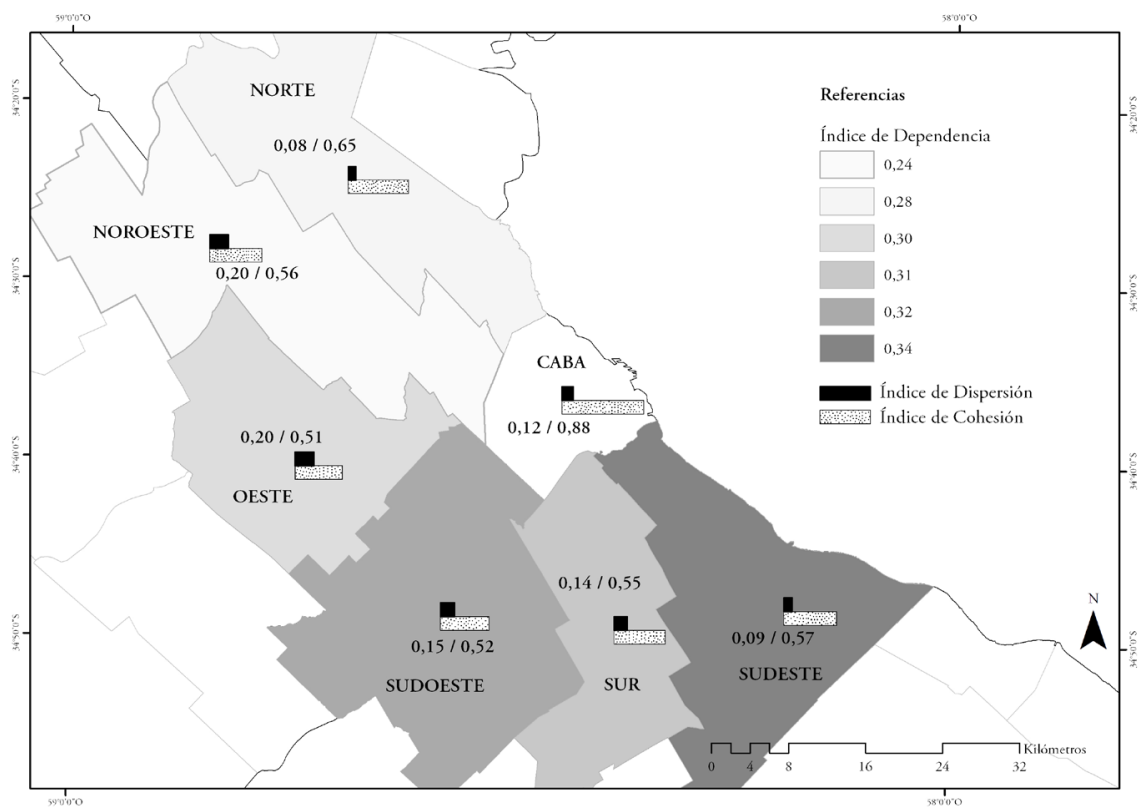

FUENTE ELABORACIÓN PROPIA 
TABLA 3 | Clasificación de los corredores según el grado de incidencia de los subcentros, considerando la evolución de los índices de movilidad y concentración laboral

\begin{tabular}{|l|c|c|c|c|c|}
\hline CORREDOR & $\begin{array}{c}\text { EMPLEO } \\
\text { POR I.OOO } \\
\text { HABITANTES, } \\
\text { 2OIO }\end{array}$ & $\begin{array}{c}\text { VARIACIÓN } \\
\text { EMPLEO } \\
\text { 2OOI-2OIO }\end{array}$ & $\begin{array}{c}\text { ÍNDICE DE } \\
\text { COHESIÓN- } \\
\text { ÍNDICE DE } \\
\text { DEPENDENCIA }\end{array}$ & $\begin{array}{c}\text { ÍNDICE DE } \\
\text { COHESIÓN- } \\
\text { ÍNDICE DE } \\
\text { DISPERSIÓN }\end{array}$ & $\begin{array}{c}\text { CLASIFICACIÓN } \\
\text { DE LAS ÁREAS DE } \\
\text { INFLUENCIA SEGÚN } \\
\text { INCIDENCIA DE LOS } \\
\text { SUBCENTROS }\end{array}$ \\
\hline Norte & 521,0 & 73,1 & 0,37 & 0,57 & Alta \\
\hline Noroeste & 497,7 & 94,2 & 0,32 & 0,37 & Alta \\
\hline Sur & 489,1 & 87,4 & 0,24 & 0,41 & Media alta \\
\hline Sudeste & 474,4 & 101,8 & 0,23 & 0,48 & Media baja \\
\hline Oeste & 481,7 & 103,9 & 0,21 & 0,31 & Media baja \\
\hline Sudoeste & 495,4 & 171,7 & 0,20 & 0,37 & \\
\hline
\end{tabular}

FUENTE ELABORACIÓN PROPIA

El corredor noroeste destaca por presentar la menor dependencia funcional (24\%), siendo el segundo en empleo por cada mil habitantes. Sobresale individualmente el partido de Hurlingham, donde la mayor proporción de viajes laborales (41\%) se dispersa hacia otros partidos; en particular hacia Morón, que recibe el 33\% de esos flujos. Esta situación encuentra clara explicación en la inercia que la historia del propio partido imprime a su dinámica de movilidad laboral. En 1994, por ley provincial se creó el municipio de Hurlingham y también el de Ituzaingo (ambos pertenecientes al corredor oeste), a partir de la división del partido de Morón. Esa decisión política separó legalmente procesos y mercados de trabajo que de hecho siguen siendo compartidos. Este tipo de interacciones explica que el corredor noroeste presente un índice de dispersión del $20 \%$.

Como áreas de influencia de incidencia media-alta de los subcentros se encuentran los corredores sur y sudeste. En este último, si bien el $57 \%$ de los flujos laborales se realiza dentro del corredor, la dependencia funcional es relativamente alta (34\%). Esto probablemente se deba al influjo individual del partido de Avellaneda, limítrofe a la CABA, cuyo índice de dependencia roza el 49\%. El corredor sur muestra una situación similar, pero aquí los índices de dependencia y cohesión son algo más bajos, por una mayor importancia de las dinámicas de dispersión, en particular dirigidas hacia el eje sudeste.

Finalmente, como áreas de influencia de incidencia media-baja se clasifican los corredores oeste y sudoeste. Estos ejes presentan los menores índices de cohesión ( $51 \%$ y $52 \%$, respectivamente) en comparación con el resto de los corredores, y los índices de dependencia son del orden del 30\% y 32\%. En el oeste, esta relativa mayor dependencia puede ser tributaria de lo que ocurre en uno de los subcentros, Morón, que individualmente presenta un índice de dependencia del 35\%. Morón, aunque no es colindante a la CABA, se encuentra bien conectado a ella a través de la Autopista Oeste, las Rutas 7 y 200 y el ferrocarril Sarmiento, lo que explica los importantes flujos hacia la ciudad central. El corredor sudoeste destaca por registrar las mayores 
variaciones en términos de aumento del empleo entre 2001 y 2010, y es de suponer que una parte importante del mismo es absorbido por el propio corredor, aunque sí hay un porcentaje (no mayoritario) que es captado por la ciudad central.

Lo dicho hasta ahora pone de manifiesto la importancia de los subcentros en la estructuración metropolitana de Buenos Aires, por lo que es posible afirmar la existencia de verdaderas pautas de policentrismo en el crecimiento de la principal aglomeración urbana argentina. Ahora, pues, queda conocer las particularidades de las relaciones entre las áreas de influencia de los subcentros y la ciudad central. En la siguiente sección se realiza esta caracterización.

\section{Caracterizando las relaciones funcionales en las áreas de influencia}

Teniendo en cuenta el tipo de relación laboral (tabla 4), el tipo de ocupación (tabla 5) y el nivel educativo (tabla 6) de los trabajadores implicados en los flujos de movilidad laboral, se demuestra que existen diferencias sustanciales en la capacidad de cada corredor para contener, expulsar y atraer diferentes tipos de trabajadores. Es decir, que la funcionalidad de los subcentros no es equivalente en las distintas áreas de influencia.

\section{Por tipo de relación laboral}

El corredor norte destaca por presentar el más alto índice de cohesión interna entre los asalariados (65\%); y, exceptuando los del oeste y el sudoeste, este índice supera el 50\%, lo que revela la potencia de los corredores para retener a sus trabajadores asalariados. En el caso de los cuentapropistas, la capacidad de autocontención de los corredores respecto a este colectivo es más pronunciada; los mayores índices de cohesión se registran en los corredores sur (67\%) y sudeste (63\%), aunque en general la cohesión es acentuada en todos los ejes (los índices están próximos al 60\% o lo superan).

TABLA 4 Índices de movilidad laboral por corredores, según tipo de relación laboral

\begin{tabular}{|l|l|c|c|c|}
\hline \multirow{2}{*}{ CORREDOR } & \multicolumn{1}{|c|}{$\begin{array}{c}\text { TIPO DE RELACIÓN } \\
\text { LABORAL }\end{array}$} & $\begin{array}{c}\text { ÍNDICE DE } \\
\text { COHESIÓN }\end{array}$ & $\begin{array}{c}\text { ÍNDICE DE } \\
\text { DEPENDENCIA }\end{array}$ & $\begin{array}{c}\text { ÍNDICE DE } \\
\text { DISPERSIÓN }\end{array}$ \\
\hline \multirow{3}{*}{ Norte } & Asalariados & 0,65 & 0,28 & 0,08 \\
\cline { 2 - 5 } & Cuenta propia & 0,60 & 0,31 & 0,09 \\
\hline \multirow{3}{*}{ Noroeste } & Asalariados & 0,54 & 0,27 & 0,20 \\
\cline { 2 - 5 } & Cuenta propia & 0,59 & 0,20 & 0,21 \\
\hline \multirow{3}{*}{ Sur } & Asalariados & 0,50 & 0,35 & 0,15 \\
\cline { 2 - 5 } & Cuenta propia & 0,67 & 0,21 & 0,12 \\
\hline \multirow{3}{*}{ Sudeste } & Asalariados & 0,54 & 0,37 & 0,09 \\
\cline { 2 - 5 } & Cuenta propia & 0,63 & 0,29 & 0,08 \\
\hline \multirow{3}{*}{ Oeste } & Asalariados & 0,47 & 0,33 & 0,21 \\
\cline { 2 - 5 } & Cuenta propia & 0,60 & 0,22 & 0,17 \\
\hline \multirow{2}{*}{ Sudoeste } & Asalariados & 0,48 & 0,35 & 0,17 \\
\cline { 2 - 5 } & Cuenta propia & 0,60 & 0,29 & 0,12 \\
\hline
\end{tabular}

FUENTE ELABORACIÓN PROPIA 
La situación descrita se corresponde con que la dependencia funcional respecto a la CABA, si bien es alta, no supera en ningún caso el $40 \%$ para el colectivo de los asalariados y el 31\% para el de los cuentapropistas. Con respecto a la dispersión, los mayores valores en el conjunto de asalariados se registran en los corredores oeste, noroeste y sudoeste $(21 \%, 20 \%$ y $17 \%$, respectivamente), y en el grupo de cuentapropistas se registran en el noroeste y oeste (21\% y $17 \%$, respectivamente).

TABLA 5 | Índices de movilidad laboral por corredores, según tipo de ocupación

\begin{tabular}{|c|c|c|c|c|c|c|c|}
\hline \multirow[b]{2}{*}{ CORREDOR } & \multirow{2}{*}{$\begin{array}{c}\text { TIPO DE } \\
\text { OCUPACIÓN }\end{array}$} & \multicolumn{3}{|c|}{ ASALARIADOS } & \multicolumn{3}{|c|}{ CUENTA PROPIA } \\
\hline & & COHESIÓN & $\begin{array}{l}\text { DEPEN- } \\
\text { DENCIA }\end{array}$ & $\begin{array}{l}\text { DISPER- } \\
\text { SIÓN }\end{array}$ & COHESIÓN & $\begin{array}{l}\text { DEPEN- } \\
\text { DENCIA }\end{array}$ & $\begin{array}{l}\text { DISPER- } \\
\text { SIÓN }\end{array}$ \\
\hline \multirow{3}{*}{ Norte } & Baja cualificación & 0,70 & 0,21 & 0,09 & 0,79 & 0,14 & 0,07 \\
\hline & Media cualificación & 0,67 & 0,26 & 0,07 & 0,66 & 0,22 & 0,11 \\
\hline & Alta cualificación & 0,50 & 0,41 & 0,09 & 0,38 & 0,54 & 0,08 \\
\hline \multirow{3}{*}{ Noroeste } & Baja cualificación & 0,56 & 0,23 & 0,21 & 0,65 & 0,18 & 0,17 \\
\hline & Media cualificación & 0,53 & 0,28 & 0,19 & 0,59 & 0,2 & 0,21 \\
\hline & Alta cualificación & 0,52 & 0,30 & 0,17 & 0,5 & 0,22 & 0,29 \\
\hline \multirow{3}{*}{ Sur } & Baja cualificación & 0,54 & 0,32 & 0,14 & 0,70 & 0,21 & 0,09 \\
\hline & Media cualificación & 0,47 & 0,37 & 0,16 & 0,68 & 0,19 & 0,13 \\
\hline & Alta cualificación & 0,57 & 0,33 & 0,09 & 0,50 & 0,33 & 0,18 \\
\hline \multirow{3}{*}{ Sudeste } & Baja cualificación & 0,57 & 0,34 & 0,10 & 0,64 & 0,27 & 0,1 \\
\hline & Media cualificación & 0,53 & 0,38 & 0,09 & 0,66 & 0,26 & 0,08 \\
\hline & Alta cualificación & 0,51 & 0,39 & 0,10 & 0,44 & 0,44 & 0,11 \\
\hline \multirow{3}{*}{ Oeste } & Baja cualificación & 0,46 & 0,3 & 0,24 & 0,62 & 0,19 & 0,2 \\
\hline & Media cualificación & 0,47 & 0,32 & 0,21 & 0,55 & 0,32 & 0,13 \\
\hline & Alta cualificación & 0,41 & 0,43 & 0,15 & 0,65 & 0,18 & 0,17 \\
\hline \multirow{3}{*}{ Sudoeste } & Baja cualificación & 0,45 & 0,39 & 0,16 & 0,60 & 0,27 & 0,14 \\
\hline & Media cualificación & 0,49 & 0,34 & 0,17 & 0,60 & 0,30 & 0,11 \\
\hline & Alta cualificación & 0,49 & 0,34 & 0,17 & 0,73 & 0,15 & 0,12 \\
\hline
\end{tabular}

FUENTE ELABORACIÓN PROPIA

\section{Por tipo de ocupación}

Destacan entre el colectivo de los asalariados las siguientes pautas: (i) los trabajadores de baja y media cualificación del corredor norte son los que mayor cohesión presentan, lo que se corresponde con una mayor dependencia hacia la CABA de los trabajadores con alta cualificación; (ii) el sudoeste y el sur presentan tasas de retención de trabajadores con alta cualificación por encima de la media de cada corredor; (iii) el oeste, el norte, y en menor medida el sudeste y el noroeste, presentan fuerte dependencia (por encima de la media) hacia la CABA con respecto a los trabajadores con alta cualificación; en el norte y el noroeste, particularmente en los partidos de Tigre, Escobar y Pilar, se concentra el mayor porcentaje de emprendimientos inmobiliarios de tipo gated community, que constituyen áreas residenciales privadas con 
las infraestructuras necesarias para conformar una especie de ciudad privada dentro de la ciudad y cuyos residentes son familias de altos ingreso (véase la operación Nordelta en el partido de Tigre) (Janoschka, 2002, 2003; Ríos \& Pírez, 2008); y (iv) la movilidad de trabajadores hacia corredores distintos al de residencia es más relevante para los trabajadores de baja cualificación del oeste y noroeste.

Entre el colectivo de cuentapropistas destaca que: (i) los que poseen baja y media cualificación y que residen en el corredor norte son los que encuentran allí mismo su principal destino laboral, destacando una significativa proporción de los más altamente cualificados que se trasladan diariamente hacia la CABA (54\%); (ii) los trabajadores altamente cualificados y residentes en el sudoeste y oeste trabajan en una proporción significativa en el propio corredor, lo cual muestra la capacidad de retención de este tipo de trabajadores; (iii) la CABA es el principal destino de los trabajadores más cualificados residentes en el sudeste y sur; y (iv) los trabajadores con más cualificación y que residen en el noroeste, sur y oeste se trasladan en mayor proporción que otros trabajadores a corredores diferentes al de residencia.

\section{Por nivel de instrucción}

Destacan las siguientes pautas: (i) en los corredores norte, noroeste, oeste y sudeste, a medida que aumenta el grado de instrucción, los índices de cohesión interna se reducen; (ii) en los corredores sur y sudoeste, un porcentaje significativo de trabajadores con instrucción alta (57\%) desempeña su actividad en el mismo corredor en que reside; (iii) en general, en todos los corredores se observa que la mayor movilidad hacia la CABA se produce entre los colectivos con instrucción media y alta; y (iv) la movilidad hacia otros corredores distintos al de residencia es heterogénea; por ejemplo, los trabajadores residentes en el sur y sudeste que realizan viajes cotidianamente son aquellos sin instrucción y con instrucción baja, mientras que los que mayor movilidad presentan hacia otros corredores son los que residen en el sudoeste y tienen instrucción alta, y los que residen en el noroeste con instrucción media y alta.

TABLA 6 | Índices de movilidad laboral por corredores, según nivel de instrucción

\begin{tabular}{|l|l|c|c|c|}
\hline \multirow{4}{*}{ CORREDOR } & \multicolumn{1}{c|}{$\begin{array}{c}\text { NIVEL DE } \\
\text { INSTRUCCIÓN }\end{array}$} & COHESIÓN & DEPENDENCIA & DISPERSIÓN \\
\hline \multirow{4}{*}{ Norte } & Sin instrucción & 0,74 & 0,17 & 0,09 \\
\cline { 2 - 5 } & Instrucción baja & 0,76 & 0,17 & 0,07 \\
\cline { 2 - 5 } & Instrucción media & 0,64 & 0,28 & 0,08 \\
\cline { 2 - 5 } & Instrucción alta & 0,48 & 0,43 & 0,09 \\
\hline \multirow{3}{*}{ Noroeste } & Sin instrucción & 0,64 & 0,20 & 0,16 \\
\cline { 2 - 5 } & Instrucción baja & 0,57 & 0,23 & 0,20 \\
\cline { 2 - 5 } & Instrucción media & 0,53 & 0,26 & 0,21 \\
\cline { 2 - 5 } & Instrucción alta & 0,48 & 0,32 & 0,20 \\
\hline
\end{tabular}


(continuación)

\begin{tabular}{|l|l|c|c|c|}
\hline \multirow{4}{*}{ CORREDOR } & \multicolumn{1}{c|}{$\begin{array}{c}\text { NIVEL DE } \\
\text { INSTRUCCIÓN }\end{array}$} & COHESIÓN & DEPENDENCIA & DISPERSIÓN \\
\hline \multirow{4}{*}{ Sur } & Sin instrucción & 0,58 & 0,25 & 0,17 \\
\cline { 2 - 5 } & Instrucción baja & 0,57 & 0,30 & 0,14 \\
\cline { 2 - 5 } & Instrucción media & 0,48 & 0,37 & 0,15 \\
\cline { 2 - 5 } & Instrucción alta & 0,57 & 0,31 & 0,11 \\
\hline \multirow{4}{*}{ Sudeste } & Sin instrucción & 0,61 & 0,29 & 0,10 \\
\cline { 2 - 5 } & Instrucción baja & 0,58 & 0,32 & 0,10 \\
\cline { 2 - 5 } & Instrucción media & 0,53 & 0,38 & 0,08 \\
\cline { 2 - 5 } & Instrucción alta & 0,52 & 0,40 & 0,08 \\
\hline \multirow{5}{*}{ Oeste } & Sin instrucción & 0,56 & 0,28 & 0,15 \\
\cline { 2 - 5 } & Instrucción baja & 0,51 & 0,28 & 0,21 \\
\cline { 2 - 5 } & Instrucción media & 0,46 & 0,33 & 0,21 \\
\cline { 2 - 5 } & Instrucción alta & 0,51 & 0,32 & 0,16 \\
\hline \multirow{4}{*}{ Sudoeste } & Sin instrucción & 0,54 & 0,28 & 0,15 \\
\cline { 2 - 5 } & Instrucción baja & 0,52 & 0,33 & 0,15 \\
\cline { 2 - 5 } & Instrucción media & 0,45 & 0,40 & 0,19 \\
\cline { 2 - 5 } & Instrucción alta & 0,57 & 0,24 & \\
\hline
\end{tabular}

FUENTE ELABORACIÓN PROPIA

\section{Consideraciones finales}

El proceso de reestructuración territorial de la metrópoli de Buenos Aires se ha abordado generalmente como el paso de la ciudad compacta a una ciudad que se expande sobre sus límites tradicionales, con una fuerte fragmentación socioespacial. Habitualmente, para reconocer los cambios en la estructura metropolitana bonaerense, los análisis han tomado datos poblacionales, de stocks industriales o de algún otro tipo de variable no relacional. A diferencia de estos, el presente artículo se centró en identificar y diferenciar los fenómenos de dispersión y de policentrismo presentes en la metrópoli utilizando datos relacionales, tales como los de flujos de movilidad obligada entre las diferentes partes del Buenos Aires metropolitano.

La conceptualización diferenciada de ambas pautas de crecimiento urbano ha permitido reconocer que los dos fenómenos están presentes en la metrópoli, aunque se manifiestan en distintas partes del espacio metropolitano y con distinta intensidad. Los resultados corroboran un patrón de crecimiento metropolitano mixto marcado por la dispersión residencial, especialmente hacia las coronas más alejadas de la ciudad central, y la presencia de subcentros de empleo que mantienen una dinámica interna propia que logra ejercer influencia en la estructura urbana. Particularmente en los ejes norte y noroeste se ha podido determinar que los subcentros tienen alta influencia, aunque ello ocurre también en el sur y el sudeste, donde la incidencia de los subcentros es media-alta.

Estos resultados revelan la existencia de pautas de policentrismo que se estarían dando junto con cierta revitalización reciente de la ciudad central. Esta continúa ejerciendo un papel preponderante en la dinámica espacial metropolitana, 
especialmente en relación con los flujos de trabajadores con más alta formación y en ocupaciones de mayor cualificación, provenientes preponderantemente de los corredores norte y noroeste.

Más allá de la primera corona, el crecimiento metropolitano sigue un patrón de dispersión con fuerte aumento de la población residente y también con una variación importante del empleo, pero donde no se registran subcentros relevantes capaces de generar dinámicas propias.

La existencia de subcentros con distinto grado de influencia en sus entornos respectivos da cuenta también de la concentración espacial de los flujos laborales en los corredores. En este sentido, la estructuración metropolitana policéntrica resulta positiva, ya que tiende a atenuar los costes de la dispersión asociados a las distancias y tiempos de viaje, proporcionando una reducción en los costes individuales y sociales y aportando con ello a una mejora de la calidad de vida de los residentes.

Esta realidad plantea nuevos retos desde el punto de vista de la gobernanza metropolitana, al resultar imprescindible el planteamiento de estrategias conjuntas y consensuadas entre los actores públicos vinculados a las políticas urbanas: el Estado nacional, el gobierno de la provincia de Buenos Aires, los gobiernos locales de cada uno de los partidos y, por supuesto, el gobierno de la Ciudad Autónoma de Buenos Aires. Los acuerdos básicos deberían considerar las nuevas tendencias en la organización y relación espacial señaladas en este artículo, orientando las políticas hacia medidas que, entre otros aspectos, privilegien el transporte público frente al privado con el fin de evitar la congestión y atenuar los impactos medioambientales, a medida que se consolidan y crecen los subcentros de empleo como núcleos fundamentales de la dinámica metropolitana.

Para nuestra investigación, se abren varias líneas de trabajo. Entre ellas, explorar otras formas de identificación de subcentros, incluyendo variables sectoriales, de especialización productiva y funcional; o características laborales y personales de los trabajadores, entre otras. La utilización de criterios semejantes derivaría en la posible definición de distintas redes policéntricas (como redes de cooperación, de sinergia, de complementariedad o de conocimiento) que pudieran estar articulando el espacio metropolitano. Asimismo, es posible explorar formas alternativas de medición de la interacción entre centros urbanos mediante diferentes datos de flujos que estuviesen disponibles en el futuro aportaría nuevas evidencias sobre las relaciones funcionales en el territorio.

Por último, el artículo no ha pretendido ofrecer un análisis de los factores explicativos de las actuales formas de reestructuración urbana ni de sus consecuencias. Acometer un estudio de este tipo constituye un desafío adicional, tendiente a profundizar en aspectos relativos a cómo los cambios demográficos, socioeconómicos, culturales, y aquellos que tienen lugar en las políticas públicas territoriales y sectoriales, influyen en la reorganización territorial, y también en el papel que desempeñan las economías de aglomeración y de red, en la forma en que opera el cambio estructural en el espacio metropolitano, etcétera. En otro ámbito, el estudio de las consecuencias potenciales de los modelos de crecimiento metropolitano, en términos de las disparidades socioeconómicas, la integración social y las condiciones de sustentabilidad ambiental, representa una nueva área que explorar. 


\section{Referencias bibliográficas}

Borsdorf, A. (2003). Cómo modelar el desarrollo y la dinámica de la ciudad latinoamericana. EURE, 29(86), 37-49. http://dx.doi.org/10.4067/S0250-71612003008600002

Borsdorf, A. (2005). La transformación urbana-rural en Europa. ¿Hacia una unificación espacial en postsuburbia? En C. de Mattos, O. Figueroa, A. Orellana \& G. Yáńez Werner (Eds.), Gobernanza, competitividad y redes. La gestión de las ciudades en el siglo XXI (pp. 21-30). Santiago: Pontificia Universidad Católica de Chile.

Borsdorf, A. \& Hidalgo, R. (2010). From polarization to fragmentation. Recent changes in Latin American urbanization. En P. van Lindert \& O. Verkoren (Eds.), Decentralized development in Latin America: Experiences in local governance and local development (pp. 23-34). Dordrecht, Heidelberg, Londres y Nueva York: Springer.

Burger M. J. \& Meijers, J. (2012). Form follows function? Linking morphological and functional polycentricity. Urban Studies, 49(5), 1127-1149. doi: 10.1177/0042098011407095

Ciccolella, P. (1995). Reestructuración global, transformaciones económicas en la Argentina y reterritorialización de la región metropolitana de Buenos Aires. Hacia una ciudad competitiva, globalizada y excluyente. Estudios Regionales, (43), 45-68. https://dialnet. unirioja.es/servlet/articulo?codigo $=251643$

Ciccolella, P. (1999). Globalización y dualización en la región metropolitana de Buenos Aires. Grandes inversiones y reestructuración socioterritorial en los años noventa. EURE, 24(76), 5-27. http://dx.doi.org/10.4067/S0250-71611999007600001

Ciccolella, P. \& Vecslir, L. (2012). Dinámicas, morfologías y singularidades en la reestructuración metropolitana de Buenos Aires. Revista Iberoamericana de Urbanismo, (8), 23-41. http://www.raco.cat/index.php/RIURB/article/view/267928

Clichevsky, N. (1999). Tierra vacante en Buenos Aires. Entre los loteos populares y las áreas exclusivas. International seminar on Vacant Land: Challenges and opportunities, Río de Janeiro, Brasil, 26-30 de abril de 1999. Reproducido en N. Clichevsky (Ed.), Tierra vacante en ciudades latinoamericanas. Cambridge (MA): Lincoln Institute of Land Policy, 2002.

Clichevsky, N. (2012). Acceso a la tierra urbana y políticas de suelo en el Buenos Aires metropolitano. Revista Iberoamericana de Urbanismo, (8), 59-72. http://upcommons. upc.edu/bitstream/handle/2099/13034/08_04_Clichevsky.pdf

Colella, V. (2013). Recent metropolitan transformations and territorial projects: The North Coast of Buenos Aires. Spaces and Flows: An International Journal of Urban and ExtraUrban Studies, 13(3), 1-13.

Comisión Europea, Comité de Desarrollo Territorial (1999). ETE. Estrategia Territorial Europea: hacia un desarrollo equilibrado y sostenible del territorio de la Unión Europea. Acordada en la reunión informal de Ministros responsables de ordenación del territorio en Potsdam, mayo de 1999. http://ec.europa.eu/regional_policy/sources/docoffic/ official/reports/pdf/sum_es.pdf

Cuadrado, J. R. \& Fernández, J. M. (2005). Las áreas metropolitanas frente al desafío de la competitividad. En E. Rojas, J. R. Cuadrado \& J. M. Fernández (Eds.), Gobernar las metrópolis (pp. 63-125). Washington, DC: Banco Interamericano de Desarrollo (BID). http://idbdocs.iadb.org/wsdocs/getdocument.aspx?docnum $=800392$ 
De Mattos, C. (2006). Modernización capitalista y transformación metropolitana en América Latina: cinco tendencias constitutivas. En A. Geraiges \& M. L. Silveira (Eds.), América Latina: cidade, campo e turismo (pp. 41-73). Sáo Paulo: Consejo Latinoamericano de Ciencias Sociales (Clacso). http://bibliotecavirtual.clacso.org.ar/ar/libros/edicion/ lemos/03mattos.pdf

De Mattos, C. (2010). Globalización y metamorfosis metropolitana en América Latina. De la ciudad a lo urbano generalizado. Revista de Geografia Norte Grande, (47), 81-104. http://dx.doi.org/10.4067/S0718-34022010000300005

Duranton, G. \& Puga, D. (2005). From sectoral to functional urban specialization. Journal of Urban Economics, 57(2), 343-370. doi: 10.3386/w9112

Ehrenhalt, A. (2012). The great inversion and the future of the American city. Nueva York: Knopf Doubleday Publishing Group.

Fernández-Maldonado, A. M., Romein, A., Verkoren, O. \& Parente, R. (2014). Polycentric structures in Latin American metropolitan areas: Identifying employment sub-centres. Regional Studies, 48(12), 1954-1971. doi: 10.1080/00343404.2013.786827

Florida, R. (2014). Where cities are growing faster than their suburbs. CityLab, junio 23, 2014. http://www.citylab.com/housing/2014/06/where-cities-are-growing-faster-than-theirsuburbs/372656/

Frey, W. (2014). Will this be the decade of big city growth? Brookings, mayo 23, 2014. http:// www.brookings.edu/research/opinions/2014/05/23-decade-of-big-city-growth-frey

García-López, M. A. \& Muñiz, I. (2007). ¿Policentrismo o dispersión? Una aproximación desde la nueva economía urbana. Investigaciones Regionales, (11), 25-43. http://www. aecr.org/images/ImatgesArticles/2008/02\%20Garcia\%20Lopez.pdf

Gallo, M. T., Garrido, R. \& Vivar, M. (2010). Cambios territoriales en la Comunidad de Madrid: policentrismo y dispersión. EURE, 36(107), 5-26. http://www.eure.cl/index. php/eure/article/view/1383

Gallo, M. T. \& Garrido, R. (2012). Una aproximación a la estructura urbana policéntrica en la Comunidad de Madrid. ACE, 6(18), 69-100. http://upcommons.upc.edu/ handle/2099/11682

Gonzales de Olarte, E. \& Del Pozo, J. M. (2012). Lima, una ciudad policéntrica. Un análisis a partir de la localización del empleo. Investigaciones Regionales, (23), 29-52. http:// www.redalyc.org/articulo.oa?id $=28924472002$

Green, N. (2007). Functional polycentricity: A formal definition in terms of social network analysis. Urban Studies, 44(11), 2077-2103. doi: 10.1080/00420980701518941

Janoschka, M. (2002). El nuevo modelo de la ciudad latinoamericana: fragmentación y privatización. EURE, 28(85), 11-20. http://dx.doi.org/10.4067/S025071612002008500002

Janoschka, M. (2003). Nordelta-ciudad cerrada. El análisis de un nuevo estilo de vida en el gran Buenos Aires. Scripta Nova VII (146)121. Barcelona: Universidad de Barcelona. http://www.ub.edu/geocrit/sn/sn-146(121).htm

Marmolejo, C. (2011). La estructura urbana de las principales metrópolis españolas. Análisis sobre su nivel de policentrismo a partir de la distribución del empleo. Report 11, Universitat Politècnica de Catalunya, Centre de Política de Sòl i Valoracions (cPsv). http://upcommons.upc.edu/handle/2117/15153?show=full 
Maturana, F. \& Arenas, F. (2012). El policentrismo en Chile: medición exploratoria para el sistema de ciudades de las regiones de La Araucanía, de Los Ríos y de Los Lagos. Revista de Geografia Norte Grande, (52), 37-56. http://dx.doi.org/10.4067/S071834022012000200003

Maturana, F., Vial, C. \& Poblete, D. (2012). Las ciudades y la interacción espacial, análisis exploratorio para los centros urbanos del Sur de Chile. Nadir: Revista Electrónica de Geografia Austral, 4(1), 1-18. http://revistanadir.yolasite.com/a\%C3\%B1o-4n\%C2\%BA-1-enero-julio-2012.php

Méndez, R. (2007). El territorio de las nuevas economías metropolitanas. EURE, 33(100), 51 67. doi: $10.4067 /$ S0250-71612007000300004

Mignaqui, I. (2012). Planes y proyectos territoriales. Escenarios de la metrópolis planificada. Revista Iberoamericana de Urbanismo, (8), 121-137. http://upcommons.upc.edu/ bitstream/handle/2099/13038/08_08_Mignaqui.pdf

Muñiz, I. \& García-López, M. A. (2013). Anatomía de la dispersión urbana en Barcelona. EURE, 39(116), 189-219. http://dx.doi.org/10.4067/S0250-71612013000100008

Muñiz, I., Sánchez, V. \& García-López, M-Á. (2015). Estructura espacial y densidad de población en la ZMVM, 1995-2010: evolución de un sistema urbano policéntrico. EURE, 41(122), 75-102. http://dx.doi.org/10.4067/S0250-71612015000100004

Núñez, T. \& Ruiz, G. (2013). Génesis de un proyecto. Puerto Madero, Buenos Aires. Revista Iberoamericana de Urbanismo, (9), 103-119. http://upcommons.upc.edu/ handle/2117/82571

Prévôt-Schapira, M. F. (2000). América Latina: la ciudad fragmentada. Revista de Occidente, (230-231), 25-46.

Ríos, D. \& Pírez, P. (2008). Urbanizaciones cerradas en áreas inundables del municipio de Tigre: :producción de espacio urbano de alta calidad ambiental? EURE, 34(101), 99119. doi: $10.4067 /$ S0250-71612008000100005

Roca, J., Marmolejo, C. \& Moix, M. (2009). Urban structure and polycentrism: Towards a redefinition of the sub-centres concept. Urban Studies, 46(13), 2841-2868. doi: $10.1177 / 0042098009346329$

Roca, J., Arellano, B. \& Moix, M. (2011). Estructura urbana, policentrismo y sprawl: los ejemplos de Madrid y Barcelona. Ciudad y Territorio, Estudios Territoriales, 43(168), 299-321. http://upcommons.upc.edu/bitstream/handle/2117/13579/04_CyTET_168web.pdf

Romein, A., Verkoren, O. \& Fernández-Maldonado, A. M. (2009). Polycentric metropolitan form: Application of a 'Northern' concept in Latin America. Footprint: Delft School of Design Journal, 2009(5), 127-145. http://dspace.library.uu.nl/handle/1874/289110

Subsecretaría de Planificación Territorial de la Inversiones Públicas (sspTip), Argentina (2008). Plan Estratégico Territorial Argentina 2016. Buenos Aires: Ministerio de Planificación Federal, Inversión Pública y Servicios. http://cdi.mecon.gov.ar/bases/docelec/fd1261.pdf

Torres, H. (2001). Cambios socioterritoriales en Buenos Aires durante la década de 1990. EURE, 27(80), 33-56. http://dx.doi.org/10.4067/S0250-71612001008000003

Trufello, R. \& Hidalgo, R. (2015). Policentrismo en el Área Metropolitana de Santiago de Chile: reestructuración comercial, movilidad y tipificación de subcentros. EURE, 41(122), 49-73. http://dx.doi.org/10.4067/S0250-71612015000100003 
Trullén, J. \& Boix, R. (2003). Barcelona, metrópolis policéntrica en red. Working Paper 03.03, Universidad Autónoma de Barcelona. http://www.ecap.uab.es/RePEc/doc/ wpdea0303.pdf

Vecslir, L. \& Ciccolella, P. (2011). Relocalización de las actividades terciarias y cambios en la centralidad en la Región Metropolitana de Buenos Aires. Revista de Geografía Norte Grande, (49), 63-78. http://dx.doi.org/10.4067/S0718-34022011000200005

Vecslir, L. \& Ciccolella, P. (2012). Editorial: Transformaciones territoriales recientes y reestructuración metropolitana en Buenos Aires. Revista Iberoamericana de Urbanismo, (8), 1-7. http:// upcommons.upc.edu/bitstream/handle/2099/13011/08_00_Editorial.pdf 